\title{
"Applying and validating the PTVA-3 Model at the Aeolian Islands, Italy: assessment of the vulnerability of buildings to tsunamis" published in Nat. Hazards Earth Syst. Sci., 10, 1547-1562, 2010
}

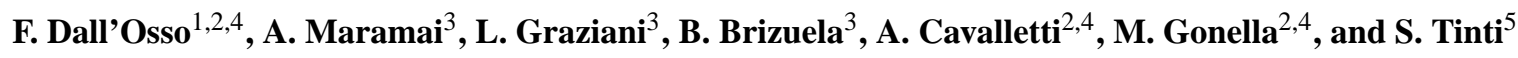 \\ ${ }^{1}$ CIRSA, Interdepartmental Centre for Environmental Sciences Research, University of Bologna, via S. Alberto 163, \\ 48100 Ravenna, Italy \\ ${ }^{2}$ IDRA, Environmental Research Institute, via Kennedy 37, 44100 Ferrara, Italy \\ ${ }^{3}$ INGV, Istituto Nazionale di Geofisica e Vulcanologia, Via di Vigna Murata 605, 00143 Roma, Italy \\ ${ }^{4}$ Med Ingegneria S.r.l., Environmental Engineering, via P. Zangheri 16, 48124 Ravenna, Italy \\ ${ }^{5}$ University of Bologna, Department of Physics, Viale Carlo Berti Pichat 8, 40127 Bologna, Italy
}

Due to some issues which occurred during the submission process, the above mentioned paper has been published with two errors in the "references" section. These are:

1. The reference to Omira et al. (2009), that is cited many times throughout the text is missing in the reference list. The reference when the paper was published is the following one:

Omira, R., Baptista, M. A., Miranda, J. M., Toto, E. A., Catita, C., and Catalao, J.: Tsunami vulnerability assessment of Casablanca-Morocco using numerical modelling and GIS tools, Nat. Hazards, doi:10.1007/s11069-009-9454-4, published online: 24 September 2009.
After the publication of the paper the above-mentioned reference was updated as follow:

Omira, R., Baptista, M. A., Miranda, J. M., Toto, E. A., Catita, C., and Catalao, J.: Tsunami vulnerability assessment of Casablanca-Morocco using numerical modelling and GIS tools, Nat. Hazards, 54, 1, 2010.

2. The reference to Olwig et al. (2007) is not listed in correct alphabetical order.

We apologize with the editor and readers for any inconvenience these mistakes might have caused.

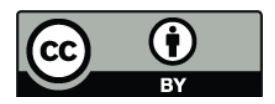

Correspondence to: F. Dall'Osso

(filippodallosso@gmail.com)

Published by Copernicus Publications on behalf of the European Geosciences Union. 